\title{
Is Cyclic Exercise Performed before Tibial Fixation Effective on Grafts during Anterior Cruciate Ligament Reconstruction?
}

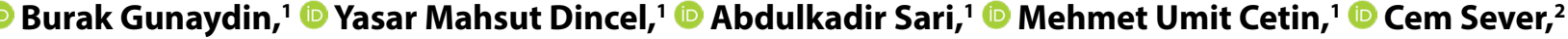 \\ Cagatay Tekin, ${ }^{3}$ (D) Melih Guney, ${ }^{1}$ (D) Yavuz Selim Kabukcuoglu' \\ 'Department of Orthopaedics and Traumatology, Tekirdag Namik Kemal University Faculty of Medicine, Tekirdag, Turkey \\ 2Department of Orthopaedics and Traumatology, Istanbul Sisli Kolan International Hospital, Istanbul, Turkey \\ ${ }^{3}$ Department of Orthopaedics and Traumatology, Cizre State Hospital, Sirnak, Turkey
}

\begin{abstract}
Objectives: The necessity of cyclic exercise to pre-stretch the autograft before tibial fixation during ACL reconstruction is unknown. In this study, we evaluated whether there was a statistically significant difference between the results of patients who underwent cyclic exercise by way of physical examinations, knee joint stability tests, and functional evaluation tests, compared with the patients who underwent $A C L$ reconstructions with or without cyclic exercise.

Methods: Between March 2016 and May 2018, 59 patients with at least eight months' follow-up of an ACL reconstruction were identified. Thirty patients (Group 1) who underwent cyclic exercise before tibial fixation and 29 patients (Group 2) who did not undergo cyclic exercise were evaluated and compared.

Results: The mean age of the patients in Group 1 and Group 2 was 25.9 (range, 18-36) years and 25.2 (range, 18-35) years, respectively. The mean follow-up period in Group 1 was 14.6 (range, 8-22) months and 13.5 months in Group 2 (range, 8-21 months).

The mean Lysholm scores of Group 1 and 2 were 95.1 (range, 83-100) and 87.1 (range, 78-100), respectively. The modified Cincinnati scores of Groups 1 and 2 were 28.7 (range, 24-30) and 26.2 (range, 21-30). The mean IKDC subjective knee evaluation scores in Groups 1 and 2 were 91.9 (range, 83-100) and 86.7 (range, 75-100). The mean thigh atrophy was $1.5 \mathrm{~cm}$ in Group 1 and $2.5 \mathrm{~cm}$ in Group 2. In Group 1, 23 patients jumped $85 \%$ of the distance compared with the intact side in the single-legged hop test, and 12 patients in Group 2 were able to hop this distance successfully.

Group 1 had statistically significantly better results in Lysholm activity scores, modified Cincinnati scores, IKDC subjective knee assessment scores, two-time IKDC activity scale results, comparison of thigh diameters, and single-legged hop tests $(p<0.05)$. No significant difference was found in other examinations and tests.

Conclusion: Cyclic exercise during the operation had a positive effect on functional scores. We believe that cyclic exercise should be added to the operative procedure.

Keywords: Anterior cruciate ligament; arthroscopic reconstruction; cyclic exercise; functional knee scoring.

Please cite this article as "Gunaydin B, Dincel YM, Sari A, Cetin MU, Sever C, Tekin C, et al. Is Cyclic Exercise Performed before Tibial Fixation Effective on Grafts during Anterior Cruciate Ligament Reconstruction? Med Bull Sisli Etfal Hosp 2020;54(4):475-482".
\end{abstract}

Address for correspondence: Burak Gunaydin, MD. Tekirdag Namik Kemal Universitesi Tip Fakultesi Ortopedi ve Travmatoloji Anabilim Dali, Tekirdag, Turkey

Phone: +90 5057887965 E-mail: docburak@gmail.com

Submitted Date: February 05, 2020 Accepted Date: February 18, 2020 Available Online Date: December 11, 2020

${ }^{\circ}$ Copyright 2020 by The Medical Bulletin of Sisli Etfal Hospital - Available online at www.sislietfaltip.org

OPEN ACCESS This is an open access article under the CC BY-NC license (http://creativecommons.org/licenses/by-nc/4.0/). 
A nterior cruciate ligament $(A C L)$ rupture occurs most frequently after a sports injury, but many etiologic factors cause these ruptures. ${ }^{[1]}$ According to the tibial adhesion site, the $A C L$ is described as two bundles, ${ }^{[2]}$ but anatomically, it consists of three bundles. ${ }^{[3-4]}$ These are the anteromedial $(\mathrm{AM})$, posterolateral $(\mathrm{PL})$, and intermediate bundle. However, the functional $A C L$ is divided into $A M$ and $\mathrm{PL}$ bundles. The AM bundle is stretched in flexion and is primarily prevents anterior to posterior displacement, and the $\mathrm{PL}$ bundle is stretched in extension and is a structure that prevents rotation of the knee. ${ }^{[2]}$ These bundles act synergistically during index movement. ${ }^{[4]}$ The intermediate bundle supports the AM and PL bundles to resist rotational forces during the knee movement. ${ }^{[5]}$

The ideal treatment option for $A C L$ reconstruction is the subject of debate concerning the perfect time of surgery. ${ }^{[6]}$ New methods have been attempted in the reconstruction of the ACL. During both single and double-bundle ACL reconstruction, grafts are fixed to the femoral tunnel, and maximum flexion and full extension movements are repeated 20 times before the tibial fixation and the grafts are stretched. ${ }^{[7,8]}$ This movement is called cyclic exercise. This exercise has two purposes; the first is to stretch the graft to a certain extent, and the second is to ensure that the graft is fully inserted into the femoral tunnel.

In the study, the graft was removed from the tibial tunnel through the endobutton of the graft in patients in Group 1 , and the maximum flexion and full extension movement were repeated 20 times. In Group 2, after the femoral fixation with endobutton, the graft was removed and stretched through the tibial tunnel but no string flexion and extension movements were performed.

Patients who underwent ligament reconstruction were retrospectively evaluated. This study aimed to investigate the effect of exercise and cyclic exercise on the results of physical examination, knee joint stability tests, and functional evaluation tests.

\section{Methods}

One hundred seven patients who underwent $A C L$ reconstruction between March 2016 and May 2018 were evaluated. The surgery of these patients was carried out by two experienced orthopedists involved in sports injury surgery. $A C L$ reconstruction was carried out using an anatomical single-bundle method. Hamstring tendons were used as grafts. In this method, an endobutton for the femoral fixation of grafts, and interference screws were applied for tibial fixation. A staple screw was used to fixing the residual tendon in the vicinity of the distal tibial tunnel. The same rehabilitation program was applied to all patients in the postoperative period. Patients with less than eight months of follow-up, those with other lesions concomitant with $\mathrm{ACL}$ lesions, those aged younger than 16 years, patients with arthrosis, $A C L$ ruptures in both knees (with or without treatment from the other knee), meniscus and cartilage lesions in the other knee (treated), and those who could not perform the single-legged hop test in the current evaluation were excluded.

Fifty-nine patients with appropriate follow-up were detected. Thirty patients (Group 1) who underwent cyclic exercise before tibial interference screw fixation during their operation and 29 patients (Group 2) without cyclic exercise were evaluated and compared. Informed consent was obtained from all individual participants included in the study. When patients came to the outpatient clinic controls, they were evaluated directly by taking radiographs (Figs. 1-4).

The results of thigh atrophy, active and passive range of motion, and stability evaluation were evaluated in the patients' knee examination. The Lachman test, which was

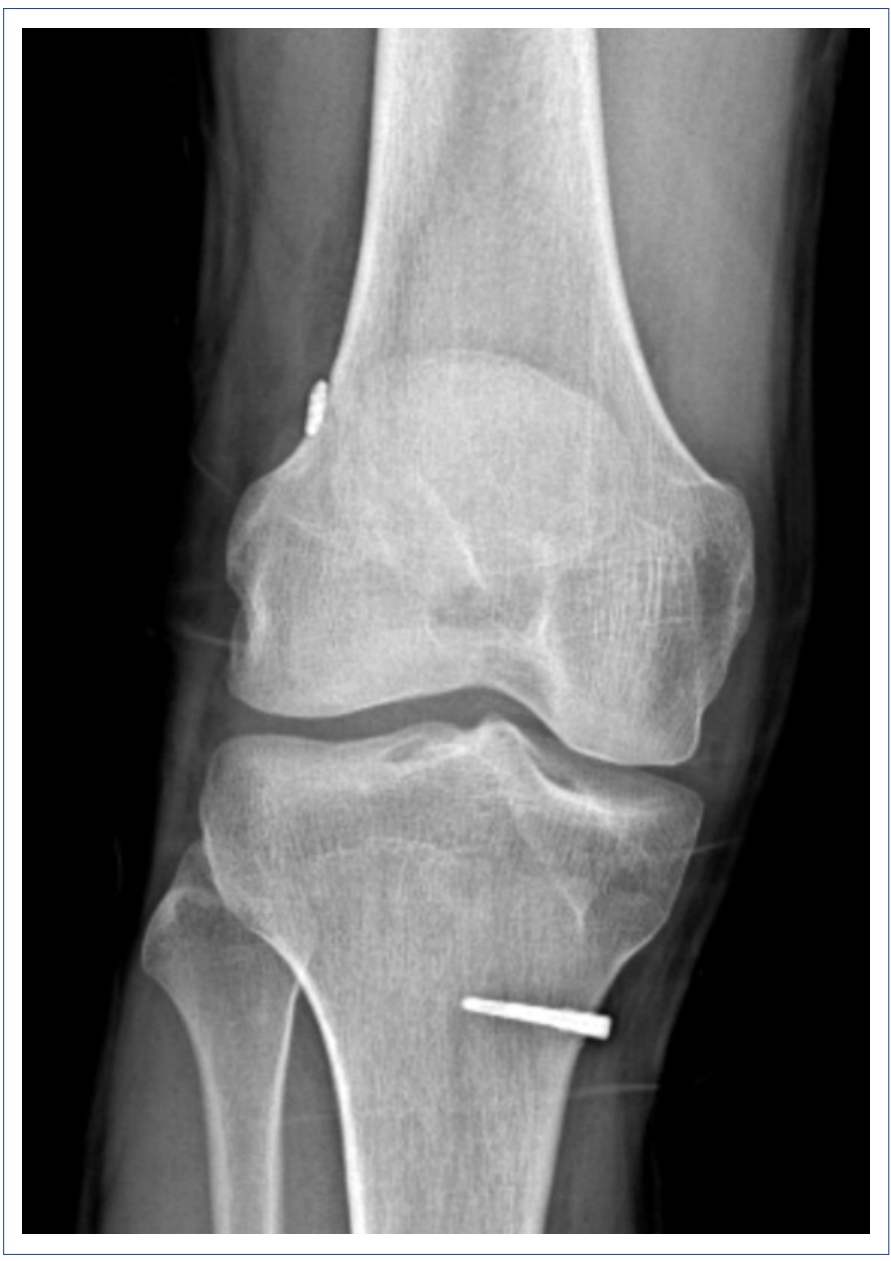

Figure 1. Ap radiography of a 21-year-old male patient for 1 year outpatient follow-up in Group 1. 


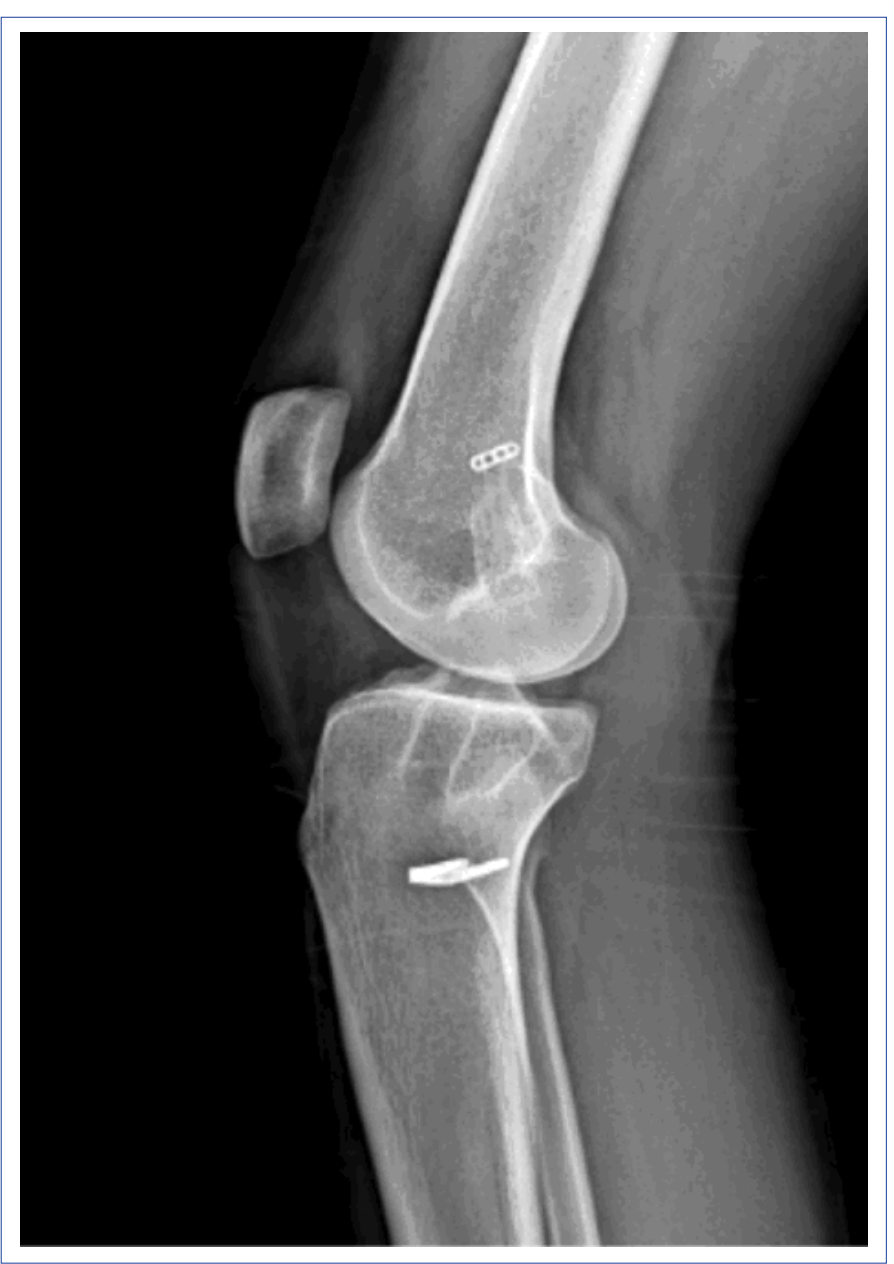

Figure 2. Lateral radiography of a 21-year-old male patient for 1 year outpatient follow-up in Group 1.

used to evaluate the postoperative stability of the patients, was evaluated as negative, $1(+), 2(+)$, and $3(+)$ as the anterior-posterior drawer test. ${ }^{[9,10]}$ Thigh atrophy was also evaluated by measuring $15 \mathrm{~cm}$ proximal of the patella's upper border around both thighs. ${ }^{[11]}$

In order to compare the findings of both groups, the International Knee Documentation Committee (IKDC) standard knee joint healing form, two-time IKDC activity scale, IKDC subjective knee form, Lysholm activity scores, and modified Cincinnati scores were used. A single orthopedist accomplished postoperative examinations of the patients.

The necessity of cyclic exercise to pre-stretch the autograft before tibial fixation during $\mathrm{ACL}$ reconstruction is unknown. As a result of these evaluations, it was evaluated whether there was a statistically significant difference between patients who did and did not undergo cyclic exercise before the tibial fixation of the graft, according to the results of knee joint stability tests, physical examinations, and functional evaluation tests.

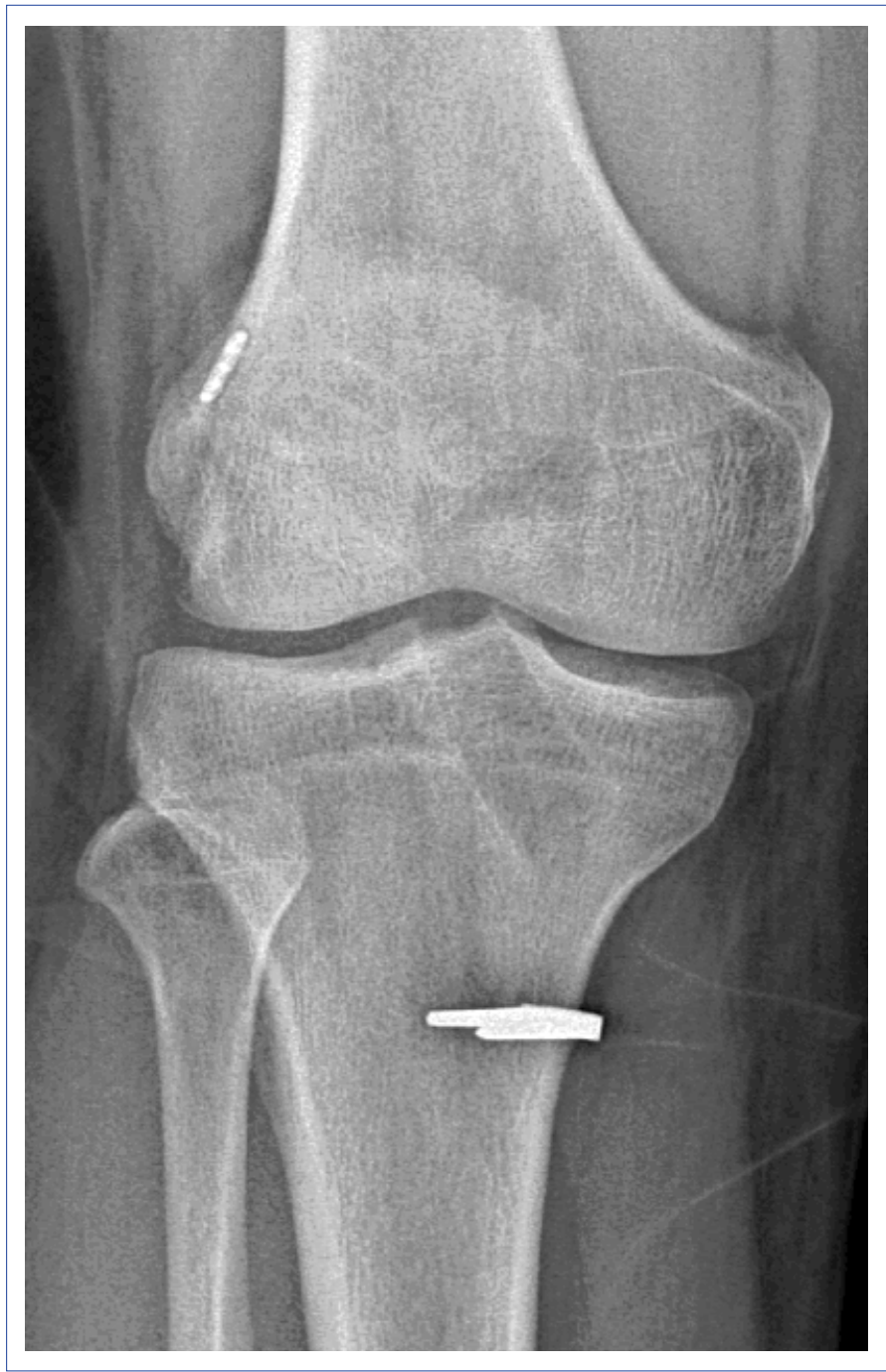

Figure 3. Ap radiography of a 23-year-old male patient for 1 year outpatient follow-up in Group 2.

\section{Statistical Analysis}

Statistical analyses were performed using the SPSS 23.0 package program. In addition to descriptive statistical methods, Mann-Whitney $U$ test, the t-test, and analysis of variance (ANOVA) were used to compare the data. Statistical significance was accepted as $p<0.05$.

\section{Results}

The mean age of patients in Groups 1 and 2 were 25.9 (range, 18-36) years and 25.2 (range, 18-35) years in Group 2. The mean follow-up period was 14.6 (range, 8-22) months in Group 1 and 13.5 (range, 8-21) months in Group 2 (Table 1). The mean age $(p=0.59)$ and duration of followup ( $p=0.45$ ) were not statistically significantly different between the groups.

Twenty-nine patients (96.6\%) in Group 1 were male. Fifteen $(50 \%)$ of these patients underwent ligament recon- 
struction in the right knee and $15(50 \%)$ in the left knee. In Group 2, 26 (89.6\%) patients were male. Fifteen (51.7\%) of these patients underwent surgery on the right knee and $14(48.2 \%)$ had surgery on the left knee. The distribution of sex $(p=0.58)$ and sides $(p=0.89)$ was not statistically significantly different between the groups.

The mean Lysholm activity score of Group 1 was $95.1 \pm 4.73$ (range, 83-100), and 87.1 \pm 7.4 (range, 78-100) of the Group 2. The mean Lysholm activity score of patients who had cyclic exercise was higher. The mean Lysholm activity scores

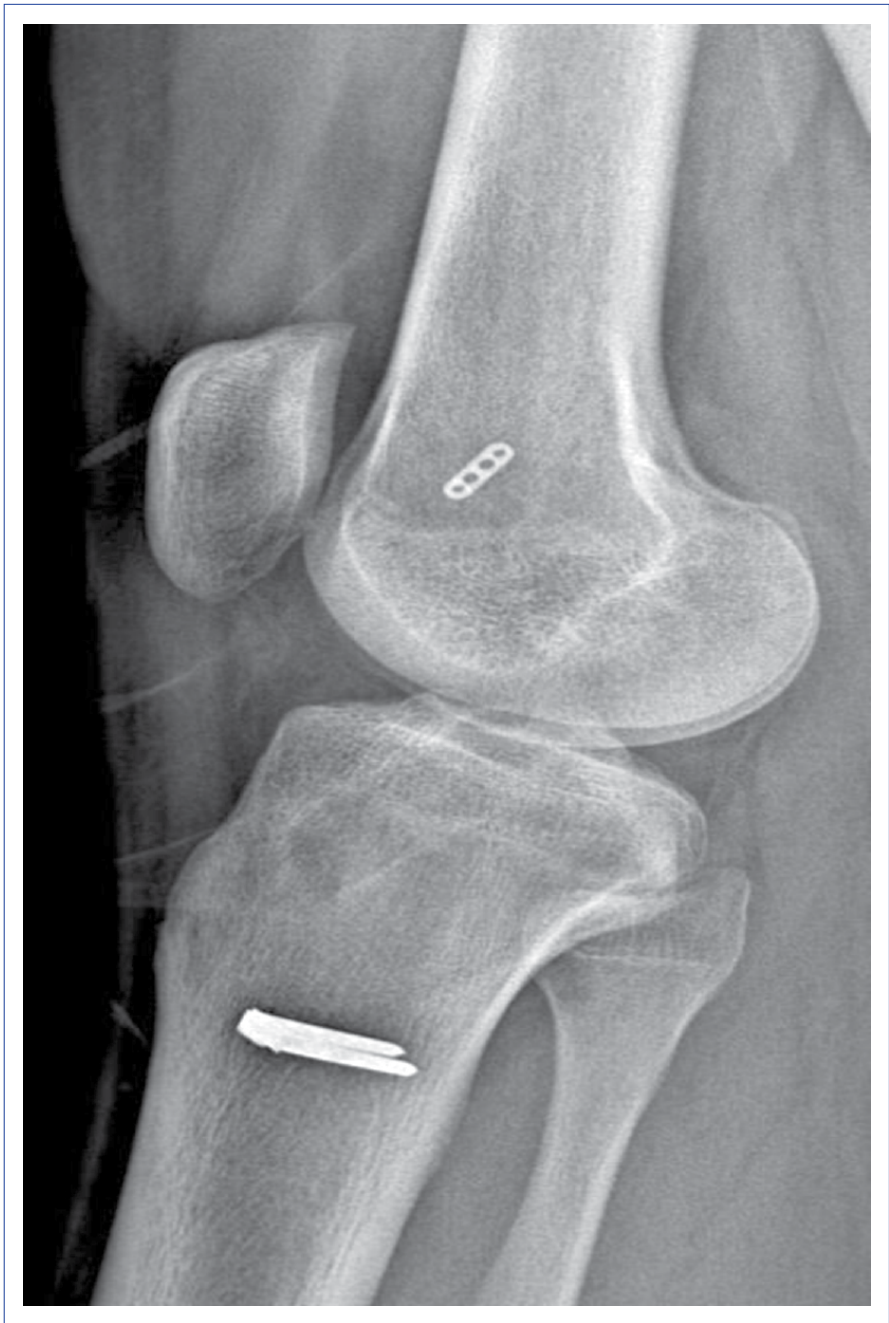

Figure 4. Lateral radiography of a 23-year-old male patient for 1 year outpatient follow-up in Group 2.

Table 1. Assessment of age and follow-up duration of patients with and without cyclic exercise

\begin{tabular}{lcc}
\hline & $\begin{array}{c}\text { with Cylic } \\
\text { exercise }(\mathbf{n}=\mathbf{3 0})\end{array}$ & $\begin{array}{c}\text { without Cylic } \\
\text { exercise }(\mathbf{n}=\mathbf{2 9})\end{array}$ \\
\hline Age (year) & $25.9 \pm 4.69$ & $25.2 \pm 4.68$ \\
Follow-up duration (month) & $14.6 \pm 4.41$ & $13.5 \pm 4.23$ \\
\hline
\end{tabular}

of patients who had cyclic exercise were statistically significantly higher than those of patients who did not undergo cyclic exercise ( $p<0.01)$ (Fig. 5).

The modified Cincinnati scores of patients in Groups 1 and 2 were $28.7 \pm 1.44$ (range, 24-30) and 26.1 \pm 3.27 (range, 21$30)$. The great majority $(96.6 \%, \mathrm{n}=29)$ of patients in group 1 were found to be at an excellent level compared with $58.6 \%(n=16)$ of patients in Group 2. The modified Cincinnati scores of patients who had cyclic exercise were statistically significantly higher than those of patients who did not undergo cyclic exercise $(p<0.01)$ (Fig. 6).

The mean IKDC subjective knee assessment score was 91.9 (range, 83-100) in Group 1 and 86.7 (range, 75-100) in Group 2. In Group 1, it was found that $46.6 \%(n=14)$ of patients were excellent, and $50 \%(n=15)$ were good, whereas $20.6 \%(n=6)$ of Group 2 were excellent, and $65.5 \%(n=15)$ had good results. The mean IKDC subjective knee assessment scores of patients who underwent cyclic exercise were statistically significantly higher than those of patients who did not undergo cyclic exercise $(p<0.01)$ (Fig. 7).

According to the IKDC score, $70 \%(n=21)$ had normal and $30 \%(n=9)$ had near-normal results in Group 1 patients and

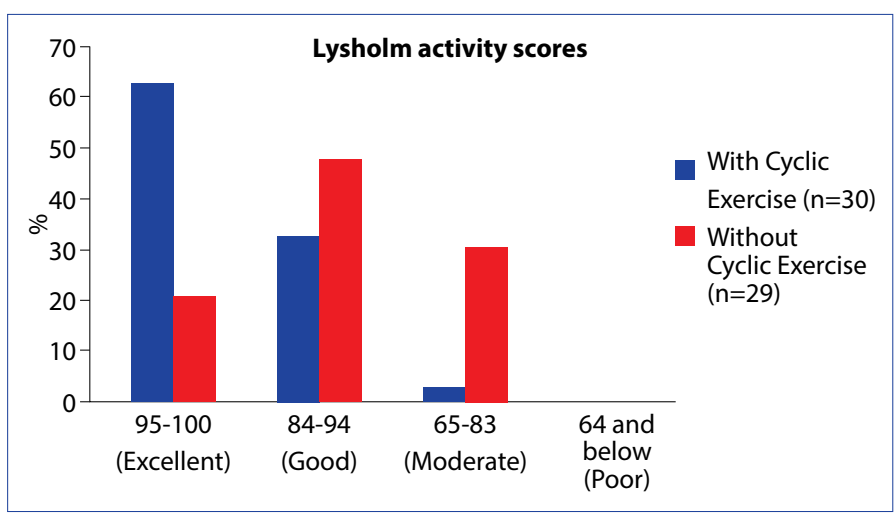

Figure 5. The results of the patients with and without cyclic exercise according to the comparative Lysholm activity scores.

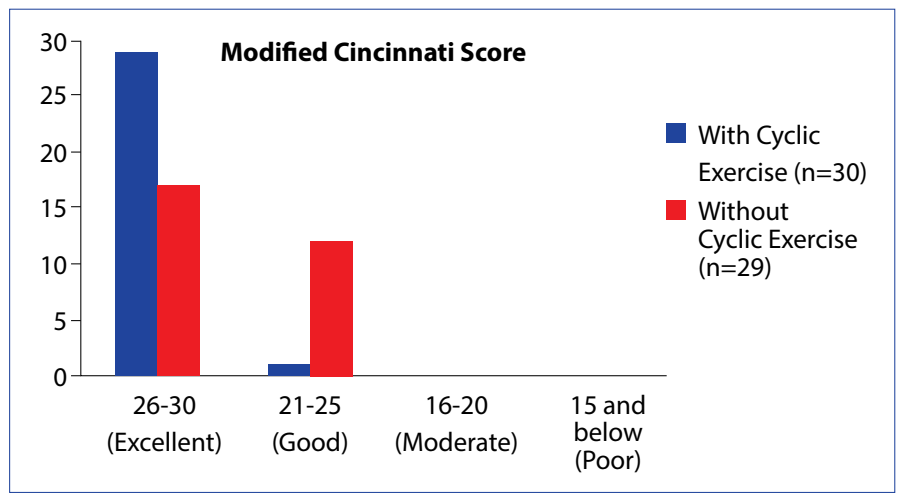

Figure 6. The results of the patients with and without cyclic exercise according to the comparative Modified Cincinnati scoring. 


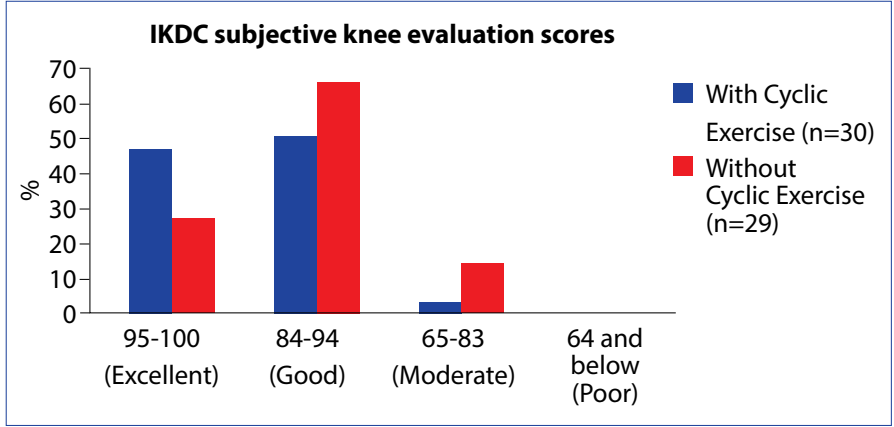

Figure 7. The results of the patients with and without cyclic exercise according to the comparative IKDC subjective knee evaluation scoring.

$58.6 \%(n=17)$ had normal and $41.4 \%(n=12)$ had near-normal results in Group 2 patients. All patients in both groups who had IKDC scoring during the last follow-up were included in A and B scores (Table 2). There was no statistically significant difference in IKDC scores between the groups $(p=0.36)$.

Although there was no statistically significant difference between the two-time IKDC activity scale ratios in the preinjury period $(p=0.43)$, the activity of patients in Group 1 was better than in those in Group 2 in the post-treatment period ( $p=0.04$ ) (Fig. 8).

The mean degree of flexion was $136.6^{\circ}$ (range, $120-160^{\circ}$ )

Table 2. The results of the patients with and without cyclic exercise according to the comparative IKDC knee examination scoring

\begin{tabular}{lcc}
\hline IKDC Score & $\begin{array}{c}\text { With Cylic } \\
\text { exercise }(\mathbf{n}=\mathbf{3 0}) \\
\%(\mathbf{n})\end{array}$ & $\begin{array}{c}\text { Without Cylic } \\
\text { exercise }(\mathbf{n = 2 9}) \\
\%(\mathbf{n})\end{array}$ \\
\hline A (Normal) & $70(21)$ & $58.6(17)$ \\
B (Near-Normal) & $30(9)$ & $41.4(12)$ \\
C (Abnormal) & 0 & 0 \\
D (Poor) & 0 & 0 \\
\hline
\end{tabular}

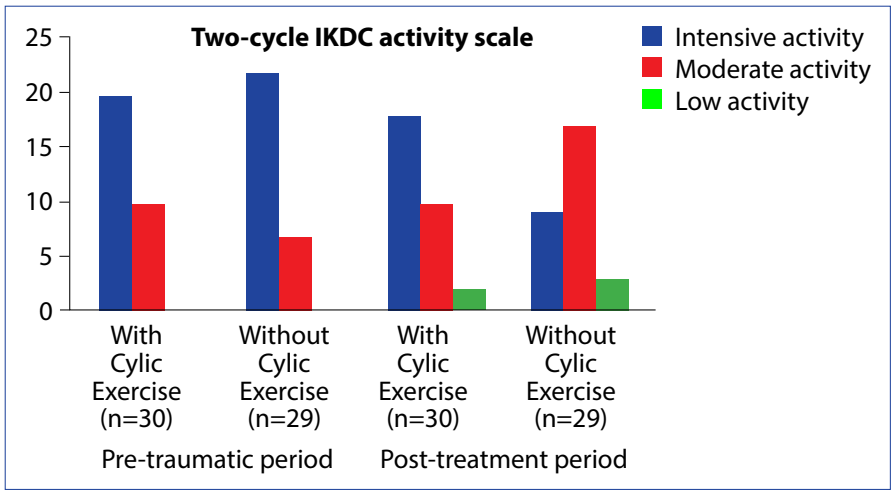

Figure 8. The results of the patients with and without cyclic exercise according to the comparative two-cycle IKDC activity scale ratios. in patients in Group 1. In Group 2, it was $134.4^{\circ}\left(120-150^{\circ}\right)$ $(p=0.43)$.

Anterior drawer tests and passive Lachman were applied to the patients during their final follow-ups. The results were evaluated as 0-2 $\mathrm{mm}:(-), 3-5 \mathrm{~mm}:(+), 6-10 \mathrm{~mm}:(++)$, and $11-15 \mathrm{~mm}(+++)$ as suggested by the American Medical Association (Table 3-4). Anterior-drawer test and Lachman test $(+++)$ of one patient undergoing Group 1 and three patients in Group 2. The ACL stability tests results were not statistically significantly different the groups $(p>0.05)$.

In the evaluation of thigh atrophy, $15 \mathrm{~cm}$ proximal of the patella's upper limit was measured by comparing the two thigh circles and divided into three degrees according to the determined length differences. The mean thigh diameters' difference was $1.56 \pm 0.91 \mathrm{~cm}$ in Group 1 and 2.51 \pm 1.13 $\mathrm{cm}$ in Group 2 (Fig. 9). The results of thigh atrophy were found to be statistically significantly different between the groups $(p<0.01)$.

The patients were asked to jump as far as they could on a single leg, and the test results of the non-operated and operated sides were compared for both knees. In Group 1, 23 patients were detected on 85\% and in Group 2, 17 patients were found below $85 \%$ (Fig. 10). The single-legged hop test results were statistically significantly different between the groups $(p<0.01)$.

The results of Lysholm activity scores, modified Cincinnati scores, IKDC subjective knee scores, two-time IKDC activity scale results, the difference between thigh diameters, and single-legged hop tests were statistically significantly better among patients who had cyclic exercise $(p<0.05)$. No statistically significant differences were found in other examinations and tests. In addition, functional scoring results

Table 3. The ACL stability test results of the patients with cyclic exercise

\begin{tabular}{lcccc}
\hline Stability test & $\begin{array}{c}(-) \\
\text { Negative } \\
\%(\mathbf{n})\end{array}$ & $\begin{array}{c}(+) \\
\text { Positive } \\
\%(\mathbf{n})\end{array}$ & $\begin{array}{c}(++) \\
\text { Positive } \\
\%(\mathbf{n})\end{array}$ & $\begin{array}{c}\text { (+++) } \\
\text { Positive } \\
\%(\mathbf{n})\end{array}$ \\
\hline Anterior Drawer & 0 & $50(15)$ & $46.7(14)$ & $3.3(1)$ \\
Passive Lachman & 0 & $46.7(14)$ & $50(15)$ & $3.3(1)$ \\
\hline
\end{tabular}

Table 4. The ACL stability test results of the patients without cyclic exercise

\begin{tabular}{|c|c|c|c|c|}
\hline Stability test & $\begin{array}{c}(-) \\
\text { Negative } \\
\%(n)\end{array}$ & $\begin{array}{c}\text { (+) } \\
\text { Positive } \\
\% \text { (n) }\end{array}$ & $\begin{array}{c}(++) \\
\text { Positive } \\
\% \text { (n) }\end{array}$ & $\begin{array}{c}(+++) \\
\text { Positive } \\
\% \text { (n) }\end{array}$ \\
\hline Anterior Drawer & 0 & $37.9(11)$ & $51.7(15)$ & $10.4(3)$ \\
\hline Passive Lachman & 0 & $41.4(12)$ & $48.2(14)$ & $10.4(3)$ \\
\hline
\end{tabular}




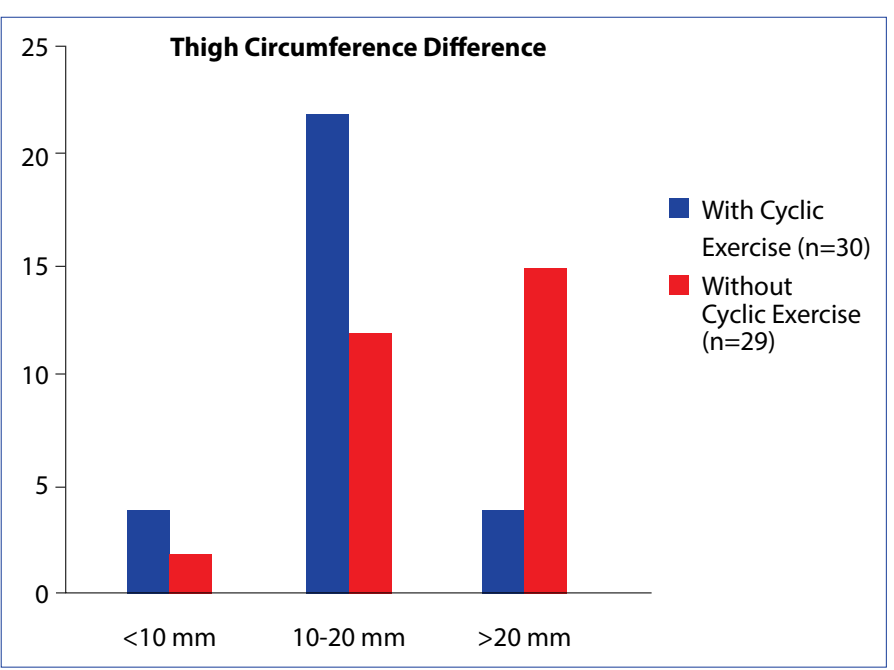

Figure 9. The comparative results of the difference between the diameters of the two thigh circumferences of the patients with and without cyclic exercise.

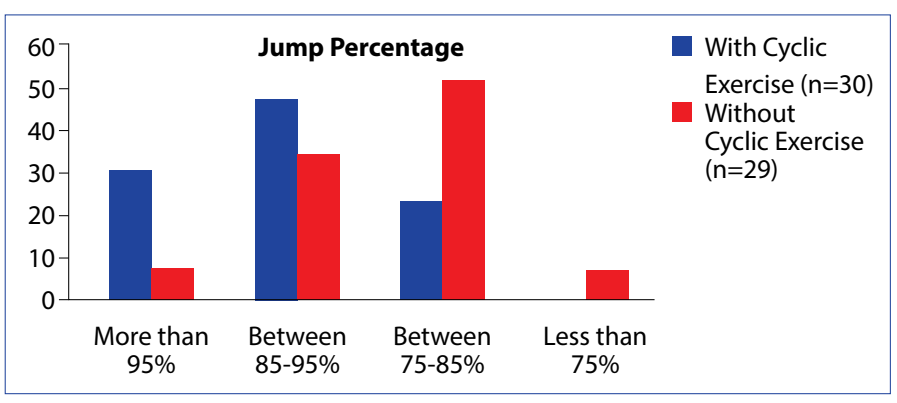

Figure 10. The comparative results of the single-legged hop test of the patients with and without cyclic exercise.

and physical examinations were found to be worse in patients who did not undergo cyclic exercises as the followup period increased.

\section{Discussion}

As the number of people interested in sports increases, the frequency of ligament damage seen in the knee increases. Among the bundles, the ACL has an important place. The $\mathrm{ACL}$ index prevents forward rotation and rotation of the knee by counteracting rotational forces. ${ }^{[2]}$ Although the frequency of $A C L$ injury varies by population. ${ }^{[12-13]}$ Treatment of ACL tears is performed conservatively or surgically. Treatment aims are to return patients to their daily and sportive activities, and as well as to protect them from new traumas. Each repeated trauma is the basis for new chondral, meniscal, and ligament damage, and thus the knee happens more unstable. ${ }^{[14-15]}$

$\mathrm{ACL}$ reconstruction is carried out using many methods and techniques. Such as single-bundle, double-bundle, and even triple-bundle reconstruction methods via using ham- string grafts, have been described in recent years. ${ }^{[16,17]}$ Many graft options are used in ACL reconstruction for patients. Patellar tendon, hamstring, quadriceps, iliotibial as autologous grafts, allografts, and synthetic grafts are commonly used graft options. ${ }^{[18-19]}$ Studies suggest that the anatomic method is the best for $A C L$ reconstruction, but successful results have been obtained with the trans-tibial method. ${ }^{[20]}$ There have been studies indicating that reconstruction of anterolateral (AL) ligament, a recently described ligament, should be performed together with $\mathrm{ACL}$ reconstruction. ${ }^{[21]}$ In all these studies, it was concluded that the ideal treatment option for $\mathrm{ACL}$ reconstruction, the ideal graft selection, and the ideal fixation method were not fully identified and that these issues were still controversial, thus further research should be performed. ${ }^{[6]}$

Significant advances have been made in ACL reconstruction, especially with the techniques' progression over the last 40 years. ${ }^{[22]}$ In a study, patients were divided into 3 groups, the single-bundle reconstruction group, the double-bundle reconstruction group, and the AL reconstruction with the single-bundle reconstruction group. As a result, it was concluded that concomitant $A C L$ reconstruction with anatomic ALL reconstruction would increase postoperative clinical outcomes. ${ }^{[20]}$ Many AL ligament reconstruction techniques have been described, and good earlystage results have been published in clinics. ${ }^{[23-25]}$ However, it is emphasized that many studies are needed to clarify the ideal technique.

The failure rate of $A C L$ reconstruction in the general population is between $1.5 \%$ and $15.3 \% .{ }^{[26-27]}$ There are several reasons affecting the success of $A C L$ reconstruction. These are meniscus and cartilage injuries, limb alignment, surgical technique, postoperative rehabilitation, and patient motivation and expectations. Johnson and Fu described failure as knees with recurrent instability, or stable but painful and limited motion. ${ }^{[28]}$ In a multicenter study, the failure of $A C L$ reconstruction was found to be the cause of failure as a result of trauma in $32 \%$ of cases, technical error in $24 \%$, biologic in-conformability disorder in $7 \%$, infection $(<1 \%)$, and the coexistence of these causes in $37 \%$ of cases. ${ }^{[29]}$ The most common reason for recurrent instability after $A C L$ reconstruction is technical errors during the first surgery. ${ }^{[30]}$ The main technical faults include inadequate tunnel placement, preliminary graft detection, high graft tension or insufficient stretching. Most (70-80\%) recurrent instability is due to inadequate tunnel location. ${ }^{[31]}$ Another reason is that the graft does not regress with appropriate tension, the factors affecting the graft length, graft elasticity, graft applied force, physiologic joint laxity, and index position at the time of detection. ${ }^{[32]}$ In single-bundle $A C L$ reconstruction, the interference screw is applied with the 
knee in 30 degrees of flexion to fix the graft to the tibial tunnel. For double-bundle reconstruction, the interference screw for fixing to the AM bundle tibial tunnel is applied with knee flexion at 30 degrees. The interference screw for fixing the PL bundle to the tibial tunnel is applied when the knee is in full extension. ${ }^{[20]}$

After ACL reconstruction, patients are advised to undergo rehabilitation and thus their muscles are strengthened. In a review, Janssen et al. investigated the effect of an accelerated rehabilitation program on clinical outcomes after $\mathrm{ACL}$ reconstruction with hamstring tendons, and the need for further investigation to determine the best balance between graft loading and graft healing at various rehabilitation stages after $A C L$ reconstruction, as well as the need to focus on assessments based on valid criteria for safe return to sports. ${ }^{[33]}$

If no additional surgical intervention was performed, such as meniscus and cartilage repair in the patients in the study, no brace was used in the postoperative period. They were allowed to mobilize with a double crutch in the early period. If additional surgical procedures were performed like meniscus repair or cartilage repair, they have used braces and they were allowed to be mobilized with a load restriction for 1 month.

In the present study, we investigated whether cyclic exercise was necessary before tibial fixation during $A C L$ reconstruction, functional evaluation test results, knee joint stability tests, and physical examinations were taken into assessment; thus, whether cyclic exercise would prevent early graft loosening was evaluated. No other publications have examined this issue.

The functional outcomes of our patients were judged retrospectively, from among those with sufficient follow-up. We found that patients with poor functional scores had not undergone cyclic exercise.

The study has some limitations. The study's first deficiency is the pivot-shift test, the results of which were not included in the study because the test was not carried out under anesthesia before and after surgery. The second deficiency is functional scoring; thigh diameters and the single-legged hop test will change with treatment of the meniscus and cartilage lesions undergoing $A C L$ reconstruction and these points are not examined in detail. The third deficiency was the retrospective evaluation of the study; the postoperative follow-up of the patients did not evaluate each patient in a predetermined period. The examination and functional scoring were performed when the patients arrived at the outpatient clinic. Finally, the lack of long-term follow-up of patients is another deficiency of the study.

\section{Conclusion}

It was determined that cyclic exercise before tibial fixation of the graft had a positive effect on functional results. Therefore, we believe that cyclic exercise should be added to $\mathrm{ACL}$ reconstruction procedures.

\section{Disclosures}

Ethics Committee Approval: The study was approved by the Namık Kemal University of Medicine non-invasive clinical research ethical committee dated 27/12/2018 and numbered 2018/152/11/02.

Peer-review: Externally peer-reviewed.

Conflict of Interest: None declared.

Authorship Contributions: Concept - B.G., A.S.; Design - B.G., M.G.; Supervision - Y.S.K., M.U.C.; Materials - B.G., A.S.; Data collection \&/or processing - C.T., M.G., Y.M.D.; Analysis and/or interpretation - Y.S.K., C.S.; Literature search - Y.M.D., C.T., M.U.C.; Writing - B.G., A.S.; Critical review - B.G., C.S.

\section{References}

1. Beynnon BD, Johnson RJ, Abate JA, Fleming BC, Nichols CE. Treatment of anterior cruciate ligament injuries, part I. Am J Sports Med 2005;33:1579-602. [CrossRef]

2. Mileswki MD, Hart JA, Miller MD. Sports Medicine. In: Miller MD, Thompson SR, Hart JA, editors. Review of Orthopaedics. 6th ed. Philadelphia: Elsevier; 2012. p. 286-7.

3. Amis AA, Dawkins GP. Functional anatomy of the anterior cruciate ligament. Fibre bundle actions related to ligament replacements and injuries. J Bone Joint Surg Br 1991;73:260-7. [CrossRef]

4. Xerogeanes JW, Takeda Y, Livesay GA, Ishibashi Y, Kim HS, Fu FH, et al. Effect of knee flexion on the in situ force distribution in the human anterior cruciate ligament. Knee Surg Sports Traumatol Arthrosc 1995;3:9-13. [CrossRef]

5. Kato Y, Ingham SJ, Maeyama A, Lertwanich P, Wang JH, Mifune Y, et al. Biomechanics of the human triple-bundle anterior cruciate ligament. Arthroscopy 2012;28:247-54. [CrossRef]

6. Geeslin AG. Editorial Commentary: All-Inside Anterior Cruciate Ligament Reconstruction: In Pursuit of Ideal Graft Fixation. Arthroscopy 2019;35:919-20. [CrossRef]

7. Zhang H, Qiu M, Zhou A, Zhang J, Jiang D. Anatomic Anterolateral Ligament Reconstruction Improves Postoperative Clinical Outcomes Combined with Anatomic Anterior Cruciate Ligament Reconstruction. J Sports Sci Med 2016;15:688-96.

8. Cohen BS, Starman JS, Fu FH. Anatomical Double-Bundle Anterior Cruciate Ligament Reconstruction. In: Harner CD, Vince KG, Fu FH, editors. Techniques in Knee Surgery. Philadelphia: Lippincott Williams \& Wilkins; 2006. p. 99-106. [CrossRef]

9. Jain DK, Amaravati R, Sharma G. Evaluation of the clinical signs of anterior cruciate ligament and meniscal injuries. Indian J Orthop 2009;43:375-8. [CrossRef]

10. Hughston JC, Andrews JR, Cross MJ, Moschi A. Classification of 
knee ligament instabilities. Part I. The medial compartment and cruciate ligaments. J Bone Joint Surg Am 1976;58:159-72.

11. Risberg MA, Ekeland A. Assessment of functional tests after anterior cruciate ligament surgery. J Orthop Sports Phys Ther 1994;19:212-7. [CrossRef]

12. Granan LP, Forssblad M, Lind M, Engebretsen $L$. The Scandinavian ACL registries 2004-2007: baseline epidemiology. Acta Orthop 2009;80:563-7. [CrossRef]

13. Gianotti SM, Marshall SW, Hume PA, Bunt L. Incidence of anterior cruciate ligament injury and other knee ligament injuries: a national population-based study. J Sci Med Sport 2009;12:622-7.

14. Altınel E. Özdemir H. Natural course of the ACL injuries. Acta Orthop Trauma Turc 1999;33;381-4.

15. Steiner ME, Brown C, Zarins B, Brownstein B, Koval PS, Stone P. Measurement of anterior-posterior displacement of the knee. A comparison of the results with instrumented devices and with clinical examination. J Bone Joint Surg Am 1990;72:1307-15.

16. Matsuo T, Mae T, Shino K, Kita K, Tachibana Y, Sugamoto K, et al. Tibiofemoral relationship following anatomic triple-bundle anterior cruciate ligament reconstruction. Knee Surg Sports Traumatol Arthrosc 2014;22:2128-35. [CrossRef]

17. Günaydın B, Eren OT, Armağan R, Sezer HB. Early comparision results of anatomical single and double bundle anterior cruciate ligament reconstruction procedures by using autogenous hamstring tendon graft. Sisli Etfal Hastan Tip Bul 2014;48:274-81.

18. Grassi A, Carulli C, Innocenti M, Mosca M, Zaffagnini S, Bait C; SIGASCOT Arthroscopy Committee. New Trends in Anterior Cruciate Ligament Reconstruction: A Systematic Review of National Surveys of the Last 5 Years. Joints 2018;6:177-87. [CrossRef]

19. Hulet C, Sonnery-Cottet B, Stevenson C, Samuelsson K, Laver $L, Z$ danowicz $U$, et al. The use of allograft tendons in primary ACL reconstruction. Knee Surg Sports Traumatol Arthrosc 2019;27:1754-70. [CrossRef]

20. Kilinc BE, Kara A, Oc Y, Celik H, Camur S, Bilgin E, Erten YT, et al. Transtibial vs anatomical single bundle technique for anterior cruciate ligament reconstruction: A Retrospective Cohort Study. Int J Surg 2016;29:62-9. [CrossRef]

21. Zhang H, Qiu M, Zhou A, Zhang J, Jiang D. Anatomic Anterolateral Ligament Reconstruction Improves Postoperative Clinical Outcomes Combined with Anatomic Anterior Cruciate Ligament
Reconstruction. J Sports Sci Med 2016;15:688-96.

22. Noyes FR, Mangine RE, Barber S. Early knee motion after open and arthroscopic anterior cruciate ligament reconstruction. Am J Sports Med 1987;15:149-60. [CrossRef]

23. Wagih AM, Elguindy AM. Percutaneous Reconstruction of the Anterolateral Ligament of the Knee With a Polyester Tape. Arthrosc Tech 2016;5:e691-7. [CrossRef]

24. Lutz C, Sonnery-Cottet B, Imbert P, Barbosa NC, Tuteja S, Jaeger $\mathrm{JH}$. Combined Anterior and Anterolateral Stabilization of the Knee With the Iliotibial Band. Arthrosc Tech 2016;5:e251-6.

25. Zein AMN, Elshafie M, Elsaid ANS, Elrefai MAE. Combined Anatomic Anterior Cruciate Ligament and Double Bundle Anterolateral Ligament Reconstruction. Arthrosc Tech 2017;6:e1229-38.

26. Persson A, Kjellsen AB, Fjeldsgaard K, Engebretsen L, Espehaug $B$, Fevang JM. Registry data highlight increased revision rates for endobutton/biosure $\mathrm{HA}$ in $\mathrm{ACL}$ reconstruction with hamstring tendon autograft: a nationwide cohort study from the Norwegian Knee Ligament Registry, 2004-2013. Am J Sports Med 2015;43:2182-8. [CrossRef]

27. Rahr-Wagner L, Thillemann TM, Pedersen AB, Lind M. Comparison of hamstring tendon and patellar tendon grafts in anterior cruciate ligament reconstruction in a nationwide population-based cohort study: results from the danish registry of knee ligament reconstruction. Am J Sports Med 2014;42:278-84. [CrossRef]

28. Johnson DL, Fu FH. Anterior cruciate ligament reconstruction: why do failures occur? Instr Course Lect 1995;44:391-406.

29. MARS Group, Wright RW, Huston LJ, Spindler KP, Dunn WR, Haas AK, et al. Descriptive epidemiology of the Multicenter ACL Revision Study (MARS) cohort. Am J Sports Med 2010;38:1979-86.

30. Harilainen A, Sandelin J. Revision anterior cruciate ligament surgery. A review of the literature and results of our own revisions. Scand J Med Sci Sports 2001;11:163-9. [CrossRef]

31. Allen CR, Giffin JR, Harner CD. Revision anterior cruciate ligament reconstruction. Orthop Clin North Am. 2003;34:79-98 [CrossRef]

32. Jaureguito JW, Paulos LE. Why grafts fail. Clin Orthop Relat Res 1996:25-41. [CrossRef]

33. Janssen RPA, van Melick N, van Mourik JBA, Reijman M, van Rhijn $\mathrm{LW}$. ACL reconstruction with hamstring tendon autograft and accelerated brace-free rehabilitation: a systematic review of clinical outcomes. BMJ Open Sport Exerc Med 2018;4:e000301. [CrossRef] 